\title{
Neotyphodium endophyte transmission to Lolium multiflorum seeds depends on the host plant fitness
}

\author{
P.E. Gundel ${ }^{\mathrm{a}, *}$, L.A. Garibaldi ${ }^{\mathrm{b}, \mathrm{c}}$, M.A. Martínez-Ghersa $^{\mathrm{a}}{ }$ C.M. Ghersa ${ }^{\mathrm{a}}$ \\ a IFEVA-Facultad de Agronomía (UBA)/CONICET, Cátedra de Ecología, Av. San Martín 4453, C1417DSE, Buenos Aires, Argentina \\ b IFEVA-Facultad de Agronomía (UBA)/CONICET, Cátedra de Ecología and Cátedra de Métodos Cuantitativos Aplicados, Av. San Martín 4453, C1417DSE, Buenos Aires, Argentina

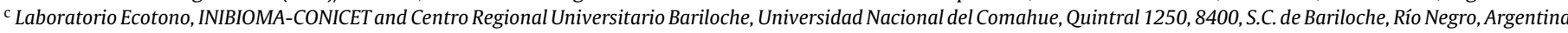

\section{A R T I C L E I N F O}

\section{Article history:}

Received 18 January 2010

Received in revised form

14 December 2010

Accepted 2 February 2011

\section{Keywords:}

Grass-endophyte symbiosis

Mutualism

Transmission efficiency

Vertical transmission

Plant genotype

Resource availability

Herbicide

\begin{abstract}
A B S T R A C T
Frequency and distribution of symbiosis in nature depend both on the direct symbiont effect on the host fitness and on its efficiency to spread within host populations (transmission). For vertically transmitted Neotyphodium fungi, the attention has been centered on the endophyte effect on host grass plants but little is known about the controls of transmission. Environmental and genetic factors have been suggested as important controls of transmission efficiency. We studied the effect of these two factors on the transmission efficiency of the Neotyphodium endophyte in Lolium multiflorum plants. Plant genotype of a host population naturally endophyte-infected (95\%) was manipulated by conducting controlled crosses with genetically distant plant populations. The resulting progeny was subjected to two types of factors, resource shortage and oxidative stress induced by an herbicide. Irrespective of plant genotype, high resource level increased seed yield per plant by 26 -fold, spike-to-seed transmission by $12 \%$, and plantto-seed transmission by $10 \%$ (not significant). Although herbicide effects could be mediated indirectly by changes in plant density or directly by oxidative stress, neither plant fitness nor transmission efficiency was affected. An interesting pattern between transmission efficiency and seed yield per plant was revealed when plants (from both experiments) were plotted together. Low yielding plants, that is plants that grew under low resource level at high plant density, showed high transmission failures whereas high yielding plants, that is plants growing at low density with and without herbicide treatment, showed high transmission rates. Transmission failures may be a consequence of the endophyte cost for host plants growing under restrictive conditions, suggesting that lower transmission efficiency may partially explain previous evidence showing lower endophyte infection frequency for grasses under stressful conditions. Host plants could be penalizing the endophyte through a competition-like mechanism, instead of depressing their own fitness.
\end{abstract}

(c) 2011 Elsevier B.V. All rights reserved.

\section{Introduction}

Obligate symbionts that are exclusively vertically transmitted, such as the endophyte fungus of many cool-season grasses, Neotyphodium, are expected to result in mutualism with high transmission efficiency (Herre et al., 1999; Gundel et al., 2008). However, infected plants usually produce a variable proportion of endophytefree seeds (do Valle Ribeiro, 1993; Welty et al., 1994; Hill et al., 2005; Afkhami and Rudgers, 2008; Gundel et al., 2009). Although failure in the Neotyphodium endophyte transmission may occur as a consequence of variation in plant genotype and environment (do Valle Ribeiro, 1993; Welty et al., 1994), to our knowledge, there

\footnotetext{
* Corresponding author. Tel.: +54 11 45248070x8125; fax: +54 1145148730

E-mail address: gundel@agro.uba.ar (P.E. Gundel).
}

are no studies that have experimentally evaluated the interaction between both factors.

Plants are normally exposed to environmental stresses that may directly impose restrictions on growth (by resources-shortage) or cause metabolism disfunction (by direct physiological damage; Harper, 1977). Likewise, the endophytic fungus has been found to be sensitive to its environment (i.e. apoplast of host plants). Endophyte growth within the host varies according to plant growth and development (di Menna and Waller, 1986; Ball et al., 1995; Puentes et al., 2007) and is affected by environmental factors such as temperature, water status and nutrient level (Ju et al., 2006; Cheplick, 2007; Rasmussen et al., 2007). Although it has been proposed that unfavorable conditions for fungus growth may cause some tillers, spikes (or panicles), spikelets and/or seeds to escape, or lose, the infection (do Valle Ribeiro, 1993; Ravel et al., 1997), it is unclear how transmission efficiency could change as a result of resource availability and level of environmental stress. 


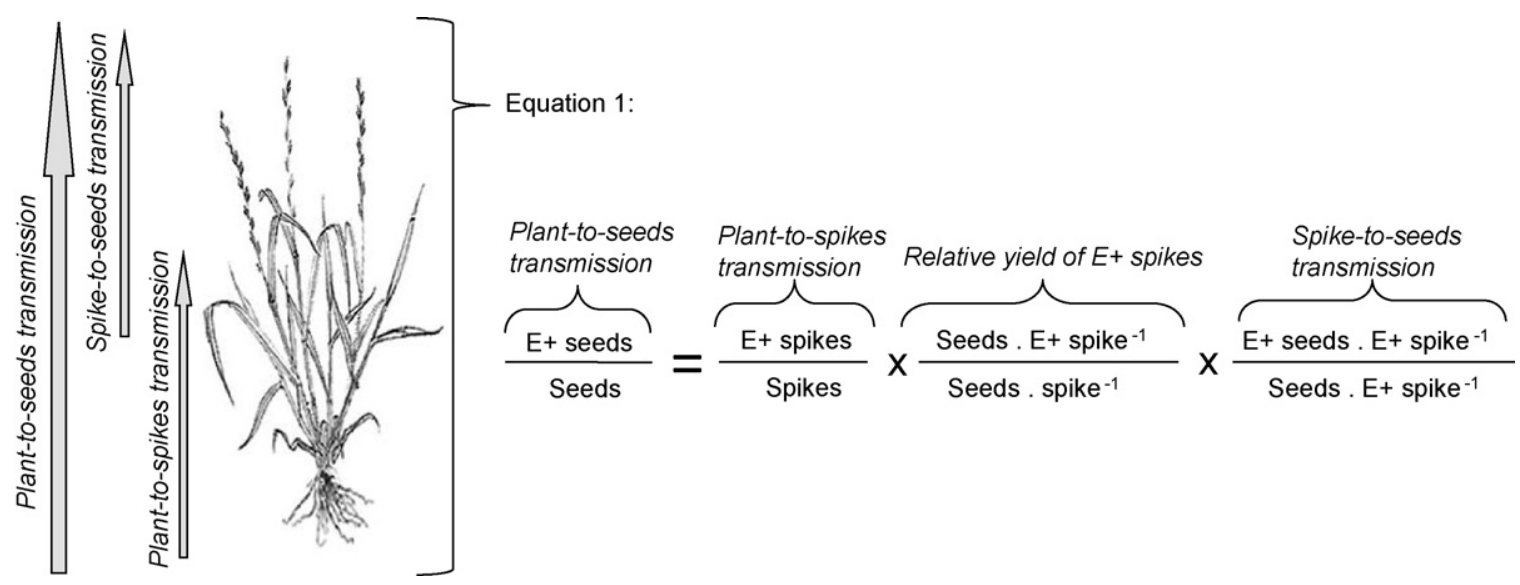

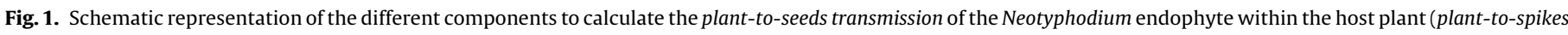

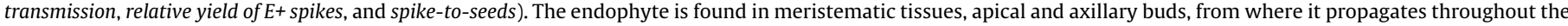
plant.

The grass-endophyte interaction has also been found to be sensitive to host plant genotype (do Valle Ribeiro, 1993; Hiatt and Hill, 1997). The grass-endophyte genetic specificity has been predicted to arise as a result of interspecific coevolution of partners at population level, and differences in gene flow rates between them are expected to increase the distance of the symbiosis from its adaptation peak. Thus, cross-pollination among plants would act as an opposite force to the local selection of genetic specificity (Faeth and Sullivan, 2003; Saikkonen et al., 2004). When host plants are pollinated by strange genotypes (outside the local population genotypes), it is expected that the endophyte encounters persistence and transmission difficulties (Saikkonen et al., 2004). Taking into account that cross-pollination is source of genetic variability and a fitness trait for allogamous plant species (Ellstrand and Schierenbeck, 2000), there should be a trade-off between this process and grass-endophyte genetic specificity at the population level (Gundel et al., 2010).

The aim of this study is to evaluate the endophyte vertical transmission efficiency at individual plant level as affected by both environmental and genetic factors. We tested the hypothesis that the endophyte transmission from plant to seeds is sensitive to the degree of environmental stress and is also controlled by the genetic specificity of both partners. In grasses, seed yield per plant is determined by the number of fertile tillers per plant (i.e. spikes), seed number per spike and mean seed weight (Harper, 1977). The proportion of endophyte-infected seeds produced by host plants may vary as a result of absence of the fungus from some fertile tillers (therefore spikes) and absence from some seeds in an infected spike (Clay and Schardl, 2002). Therefore, we assessed transmission in two separate phases: endophyte transmission from plant-tospikes and endophyte transmission from spike-to-seeds (Fig. 1). We expected not only to provide evidence of the relative impact of these two components to the entire process of transmission, but also to shed light on the controls of endophyte transmission in response to changes in the number of spikes and individual seed yield per plant.

\section{Materials and methods}

\subsection{General procedures}

This work was carried out using the cool-season annual grass Lolium multiflorum Lam. and its fungal endo-symbiont Neotyphodium occultans (Moon et al., 2000; Christensen et al., 2002). L. multiflorum, $a$ native from the Mediterranean, has expanded its range since the 17th century becoming naturalized in most of the world temperate regions. In the Argentinean Pampas, annual ryegrass populations have been growing without human assistance for more than 100 years (Gundel et al., 2009). Controlled crosses between plants from different $L$. multiflorum populations were conducted in order to achieve a range of variation in genetic factors. Two different environmental stresses were explored: stress by resource shortage (restriction for growth) and stress by diclofopmethyl herbicide that causes direct physiological damage on plants. Two modes of action have been described for this herbicide: inhibition of the acetyl-CoA carboxylase enzyme (Powles and Holtum, 1994) and oxidative stress damage (Shimabukuro et al., 1999). Many L. multiflorum populations have evolved resistance to the herbicide and the endophyte has been found to enhance the tolerance in susceptible populations (Vila-Aiub et al., 2003).

Populations of $L$. multiflorum from two different origins were used for the plant crosses. A highly endophyte-infected (95\%) population from the Inland Pampa sub-region, Argentina (Vila-Aiub et al., 2005) and the Gulf variety. The first one was reproduced during several years in an experimental field (Faculty of Agronomy, University of Buenos Aires; $34^{\circ} 35^{\prime} \mathrm{S}, 58^{\circ} 35^{\prime} \mathrm{W}$ ) in a $1 \mathrm{~m}^{2}$ plot filled with $10 \mathrm{~cm}$ top soil free of wild L. multiflorum seeds, from matured seeds hand-collected in 1998. The Gulf variety is a commercial North American variety used as forage with an early intermediate-season production cycle (Redfearn et al., 2002). An herbicide-resistant isoline has been obtained by applying high selection pressures with diclofop-methyl herbicide on the susceptible populations and successive backcrosses (Baker, personal communication). Three different populations were used for the crosses: Pampean endophyte-infected and herbicide-susceptible (Ps) harvested in December 2003, Gulf non-infected and herbicidesusceptible (Gs), and Gulf non-infected and herbicide-resistant (Gr). A molecular genetic analysis with SSR revealed that the Ps population was genetically different from Gs and $\mathrm{Gr}$ (see Appendix 1, Gundel et al., unpublished data).

\subsection{Plant crosses}

The crosses were performed in 2004, in the experimental field of the Faculty of Agronomy, University of Buenos Aires. One hundred plants of the Pampean population and 50 plants of each isoline were grown individually in $1.5 \mathrm{~L}$ pots, filled with a mixture of organic soil, sand and peat-moss (50/25/25, v/v/v) and periodically watered. At flowering time, two synchronously flowering plants were selected and isolated by covering the spike with a waxed paper bag. Since L. multiflorum is a self-incompatible species 
Table 1

Number of plant crosses, and number of seeds resulting from the crosses and corresponding endophyte infection level.

\begin{tabular}{lllllr}
\hline \multicolumn{2}{l}{ Plant crosses } & & $\begin{array}{l}\text { Number of } \\
\text { crosses }\end{array}$ & $\begin{array}{l}\text { Number of } \\
\text { seeds }\end{array}$ & $\begin{array}{l}\text { Infection level } \\
(\%)^{\mathrm{a}}\end{array}$ \\
\hline Mother & Parent & Progeny F1 & & & \\
\hline Ps & Ps & Ps(Ps) & 21 & 396 & 95 \\
& Gs & Ps(Gs) & 13 & 203 & 100 \\
& Gr & Ps(Gr) & 14 & 262 & 95 \\
\hline
\end{tabular}

a Based on 20 seeds evaluated under light microscope.

and the endophyte is maternally transmitted, it is expected that the F1 seeds collected from mother plants (always Ps) are the result of pollination by the accompanying plant and were therefore endophyte-infected (Adams et al., 2000). Twenty individual plants of the Pampean population were isolated in order to estimate the degree of self-incompatibility and the external pollen contamination. It was concluded that self-incompatibility is very high and pollen contamination low, as only 5 seeds were obtained from the whole trial. The expression of resistant phenotypes in the F1 Ps(Gr) was a confirmation that the protocol used for plant crossing had worked well (data not shown). Therefore, it was possible to change the genetic background and to transfer herbicide resistant genes from male parent plants (Ps, Gs and Gr) to mother plants (Ps). After plant crossings, the total number of seeds produced was bulked and their endophyte infection level checked (Table 1 ). In what follows, plants from each cross are designated by the male parent plant.

\subsection{Plant experiments}

During 2005, the effects of environmental and genetic factors on the Neotyphodium endophyte transmission efficiency in L. multiflorum plants were assessed in two field experiments. The first experiment was carried out to test the impact of plant genotype and resource availability on the endophyte transmission efficiency. Plants resulting from $\mathrm{Ps}(\mathrm{Ps})$ and $\mathrm{Ps}(\mathrm{Gs})$ crosses were grown in two different pot sizes 1.5 and $25.0 \mathrm{~L}$ pots (low and high resource level, respectively) with three replicates each. Since plant number per pot was constant $\left(\sim 9\right.$ plants pot $\left.^{-1}\right)$, level of resources per plant was controlled by changing pot volume (i.e. small or large pots allowed plants to have access to different levels of soil nutrients, water and radiation). The second experiment was carried out to assess the impact of plant genotype and level of stress produced by the diclofop-methyl herbicide application on the transmission efficiency. In this experiment, three replicate $25.0 \mathrm{~L}$ pots, each containing about $\sim 9$ plants resulting from $\mathrm{Ps}(\mathrm{Ps})$, $\mathrm{Ps}(\mathrm{Gs})$ and $\mathrm{Ps}(\mathrm{Gr})$, crosses were used. Herbicide at one of the following doses was applied when plants had about 3 and 4 expanded leaves: 0 (control), 70 and $140 \mathrm{~g}$ ai ha ${ }^{-1}$. The application was done with a $1 \mathrm{~L}$-constant-pressure hand-sprayer (Commercial formulation $284 \mathrm{gai} \mathrm{L}^{-1}$, Iloxan; Hoechst-Aventis, Strasbourg, France; recommended dose $1.12 \mathrm{~kg}$ ai ha $^{-1}$ ). In order to control for the herbicide effect mediated by changes in plant density, plant survival was recorded one month after herbicide application.

Both experiments started on the same date (in autumn), with seeds directly sown in soil mixture (composed of organic soil, sand and peat-moss at the same proportion as above). Endophyte infection was checked in all the plants, by looking for the fungus mycelium in the base of the oldest leaf, previously peeled and stained, under light microscope (Moon et al., 2000; Koh et al., 2006). The plants were watered and maintained in the same pot until the end of the production cycle (late spring). Both experiments were carried out outdoors in separated but contiguous places, and pots were randomly placed and frequently rotated within each experiment. The plants were allowed to be freely pollinated. Spikes were individually harvested when they reached maturity. Each spike was then threshed and the cleaned seeds weighed. Number of seeds produced per spike, spikes per plant, and final plants per pot were recorded. Seed weight was estimated by weighing three groups of 30 seeds per spike, and is reported here as the average of all of the spikes per plant.

\subsection{Endophyte transmission efficiency}

Transmission efficiency at individual plant level is the proportion of E+ seeds produced by an endophyte-infected plant (hereafter plant-to-seeds). To better characterize each step towards the whole transmission process, a set of partial calculations was performed (Fig. 1). Among others, transmission efficiency may vary because of the fungus failures to reach every spike (hereafter plantto-spikes), the fungus failures to reach all the seeds in infected spikes (hereafter spike-to-seeds), and because of differential seed production between $\mathrm{E}+$ and $\mathrm{E}-$ spikes. This latter expression is formalized in Equation (1) (Fig. 1, right side), where relative yield of $E^{+}$ spikes is the ratio between total seeds in $\mathrm{E}+$ spikes and total seeds per spike, plant-to-spikes transmission is the ratio between $\mathrm{E}+$ spikes per plant and total spikes per plant, and spike-to-seeds transmission is the ratio between $\mathrm{E}+$ seeds per $\mathrm{E}+$ spike and total seeds per $\mathrm{E}+$ spike (Fig. 1). Note that relative yield of $E+$ spikes can take three possible values: $1,>1$ and $<1$, meaning that $\mathrm{E}+$ spikes yield equal to, higher than, and lower than all the spikes in the plant.

In both experiments, we estimated endophyte transmission efficiency and its components by assessing the presence of endophyte hyphae in ten seeds per spike for all the spikes produced by a plant. Thus, sampling effort was greater with higher number of spikes per plant. Stained seeds were inspected for endophyte hyphae under light microscopy. For this purpose, seeds were incubated in sodium hydroxide $(2.5 \%)$ for $\sim 12 \mathrm{~h}$, and then stained with Rose Bengal (ethanol $5 \mathrm{~mL}$, Rose Bengal stain $0.5 \mathrm{~g}$, distilled water $95 \mathrm{~mL}$ ). This methodology has proven to be suitable for Neotyphodium endophyte determination (Koh et al., 2006). A spike was considered infected if at least one of ten examined seeds was infected. The spike was considered non-infected if the ten seeds were negative.

\subsection{Statistical analysis}

Data were analyzed using generalised linear models ( $R$ software, version 2.9.0, glm function) with the identity-link function, but with different error structures according to the response variable tested. For the first experiment, models tested the effects of plant genotype (Ps and Gs), resource level (1.5 and 25.0 L pots), and genotype $\times$ resource interaction on the endophyte transmission efficiency and its components (Fig. 1), seed yield per plant, seed weight, and number of spikes. For the second experiment, models tested the effects of plant genotype (Ps, Gs, and Gr), herbicide dose $\left(0,70\right.$, and $140 \mathrm{~g}$ ai ha $^{-1}$ of diclofop-methyl herbicide), and genotype $\times$ herbicide interaction on the same variables as in the first experiment. Changes in plant density were used as covariate. Significance was tested through sequential analysis of deviance; selected error distributions were those yielding the lowest residual deviances (Crawley, 2007). All variables were modeled using a Gaussian distribution, except for the number of spikes and the relative yield of $\mathrm{E}+$ spikes in both experiments, and yield in the second experiment, which were modeled under a Gamma error distribution. Finally, data for plants from both experiments was pooled into a single matrix to study, at the individual plant level, the association between different components of the plant-to-seeds transmission and seed yield per plant, seed weight and number of spikes by Spearman's correlations. 

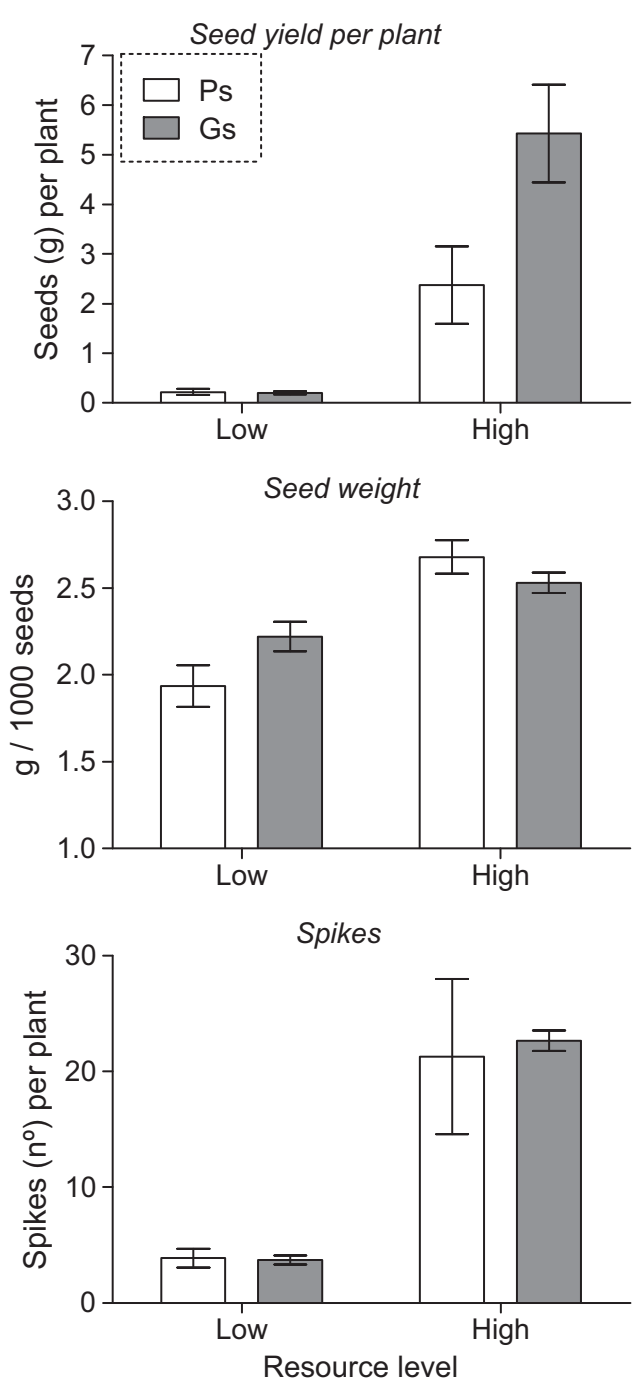

Fig. 2. The effect of low and high resource levels on seed production per plant (seed yield per plant), seed weight per plant (seed weight) and number of spikes per plant (spikes) of Lolium multiflorum plants from Ps and Gs crosses. Values are expressed per plant, and are averages for three pots ( \pm s.e.).

\section{Results}

\subsection{Effects of resource level and plant genotype}

Resource availability increased seed yield per plant $\left(F_{1,8}=32.4\right.$, $P<0.001)$ and number of spikes $\left(F_{1,8}=86.3, P<0.001\right)$ by 26 - and 6 -fold, respectively, irrespective of plant genotype (Fig. 2). Seed weight was also higher under high- than low-resource level, but this trend was only significant for Ps plants (genotype $\times$ resource: $F_{1,8}=6.3, P=0.036$ ). We found no significant interaction between plant genotype and resource level for the plant-to-seed transmission efficiency and its components $(P>0.05$; Fig. 3$)$. Plants under high resource level showed $12 \%$ higher spike-to-seeds transmission than plants with low resources $\left(F_{1,8}=4.9, P=0.058\right.$; Fig. 3$)$. A similar (non-significant) tendency ( $12 \%$ increase) was observed for plant-to-seeds transmission efficiency, whereas we did not find differences for relative yield of E+ spikes and plant-to-spikes transmission $(P>0.05)$. Overall, Ps genotype showed lower values for all transmission efficiency variables than Gs genotype; however, the former presented a marginally higher relative yield of $E+$ spikes than the latter $\left(F_{1,8}=3.5, P=0.099\right.$; Fig. 3$)$.

\subsection{Effects of herbicide dose and plant genotype}

Seed yield per plant differed among genotypes $\left(F_{2,22}=7.2\right.$, $P=0.005$ ), being on average $9.2 \mathrm{~g}$ per plant for $\mathrm{Gs}, 8.6 \mathrm{~g}$ for Ps, and $3.3 \mathrm{~g}$ for $\mathrm{Gr}$, but we found no differences in seed weight (Fig. 4). Herbicide did not affect seed yield per plant although the higher dose reduced seed weight $\left(F_{1,21}=8.2, P=0.010\right)$. Susceptible genotypes (Gs and Ps) showed a decreased plant density with an increased number of spikes per plant with herbicide dose, but we found no herbicide effect on the resistant genotype (genotype $\times$ herbicide; number of spikes: $F_{2,19}=5.7, P=0.015$; plant density: $F_{2,19}=4.4$, $P=0.026$; Fig. 4). No effect of genotype or herbicide dose on plantto-seeds transmission and its components was found, even after considering the effects of plant density as a covariate in the statistical model ( $P>0.05$; Fig. 5).

\subsection{Endophyte transmission efficiency and plant traits}

We found positive association between seed yield per plant and the efficiency of plant-to-seeds transmission and its components (Fig. 6). Of the total plants in each pot, the 77.0, 59.0 and $50.0 \%$ of them presented perfect transmission of endophyte for plant-tospikes, spike-to-seeds and plant-to-seeds, respectively. Likewise, the $82.0,88.0$ and $76.0 \%$ of the plants presented an endophyte transmission higher than 0.90 from plant-to-spikes, spike-to-seeds and plant-to-seeds, respectively. Overall, plants with low seed yield showed lower plant-to-seeds, plant-to-spikes, and spike-to-seeds transmission but higher relative yield of $\mathrm{E}+$ spikes than plants with high seed yield. Indeed, except for one outlier (17.90 $\mathrm{g}$ of seeds with a total transmission of 0.02 ), $68.0 \%$ of the plants displayed transmission levels over 0.95 , and within this group $81.8 \%$ producing more than $3 \mathrm{~g}$ of seeds, had perfect transmission efficiencies (Fig. 6), while almost half the plants producing less than $3 \mathrm{~g}$ displayed imperfect transmission. There was no particular pattern associated with plant genotype or environmental treatments. However, within the group yielding less than $3 \mathrm{~g}$, the proportion of plants with high transmission efficiency (>0.95) was $50.0 \%$ in control plants and $73.9 \%$ in herbicide treated plants (data not shown).

Seed yield per plant correlated positively with number of spikes $\left(R^{2}=0.73, P<0.001\right)$ and seed number $\left(R^{2}=0.98, P<0.001\right)$ but no correlation was found with seed weight $\left(R^{2}=0.007, P=0.408\right)$. Except for the correlation between seed number and plant-to-seeds transmission that was not statistically significant, all components of seed yield per plant (i.e. seed weight, seed number, and number of spikes) correlated positively with plant-to-seeds transmission efficiency and its components (data not shown). Seed weight showed the highest correlation with spike-to-seeds transmission $\left(r_{\mathrm{s}}=0.45, P<0.001\right)$, also correlating positively with plant-to-seeds $\left(r_{\mathrm{S}}=0.28, P=0.007\right)$ and plant-to-spikes $\left(r_{\mathrm{S}}=0.21\right.$, $P=0.040)$ transmission, and relative yield of $\mathrm{E}+$ spikes $\left(r_{\mathrm{s}}=0.25\right.$, $P=0.014)$. The number of seeds correlated positively with spike-toseeds $\left(r_{\mathrm{s}}=0.22, P=0.036\right)$ and plant-to-spikes $\left(r_{\mathrm{s}}=0.20, P=0.049\right)$ transmission but no significant correlation was found with either plant-to-seeds transmission $\left(r_{\mathrm{s}}=0.15, P=0.159\right)$ or relative yield of E+ spikes $\left(r_{\mathrm{s}}=0.14, P=0.170\right)$. The number of spikes showed positive correlations with all four variables, but effects were only significant for spike-to-seeds transmission $\left(r_{\mathrm{s}}=0.23, P=0.028\right)$.

\section{Discussion}

Knowledge of the controls of endophyte vertical transmission at individual plant level is essential to better understand both the grass-endophyte symbiosis and the determinants of the fungus infection frequency in grass populations (do Valle Ribeiro, 1993; Ravel et al., 1997; Afkhami and Rudgers, 2008; Gundel et al., 2008). 


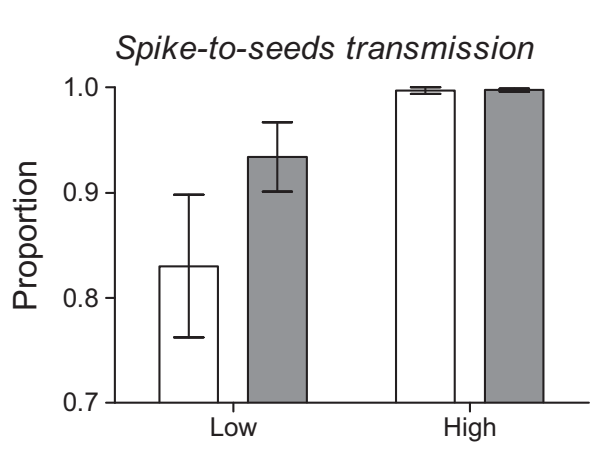

Plant-to-spikes transmission

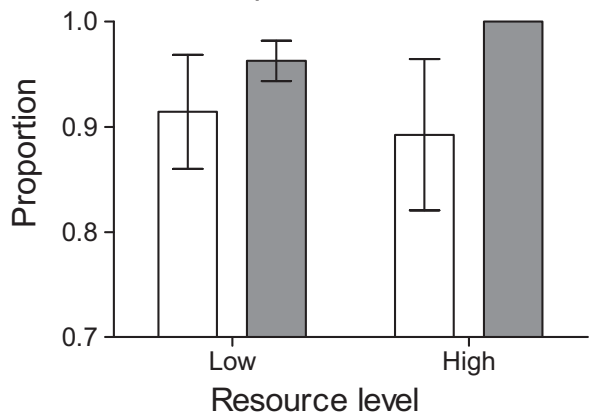

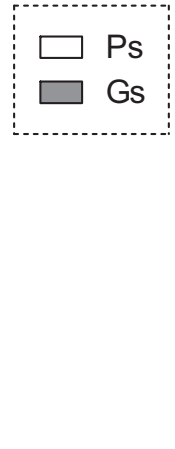

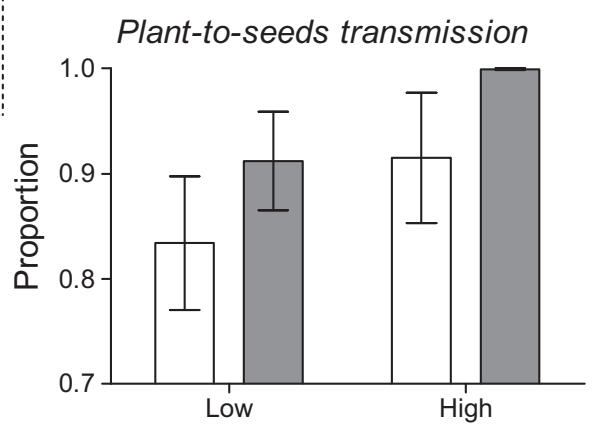

Relative yield of E+ spikes

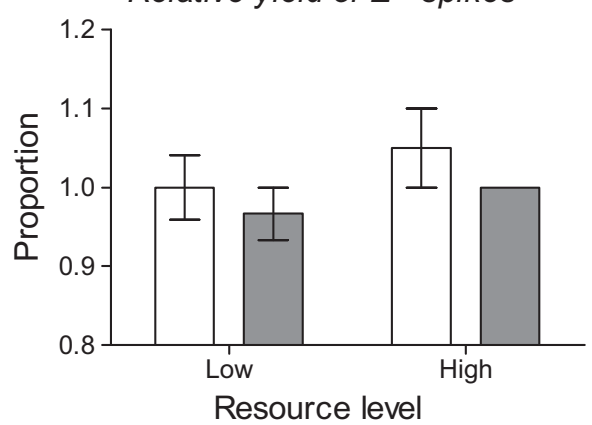

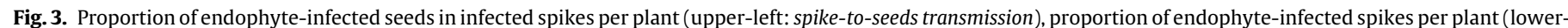

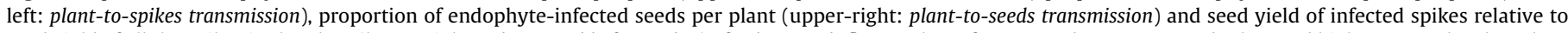

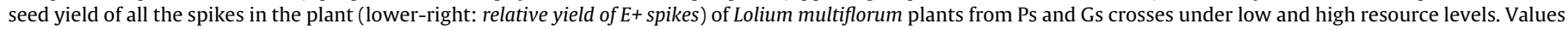
are expressed per plant, and are averages for three pots ( \pm s.e.).
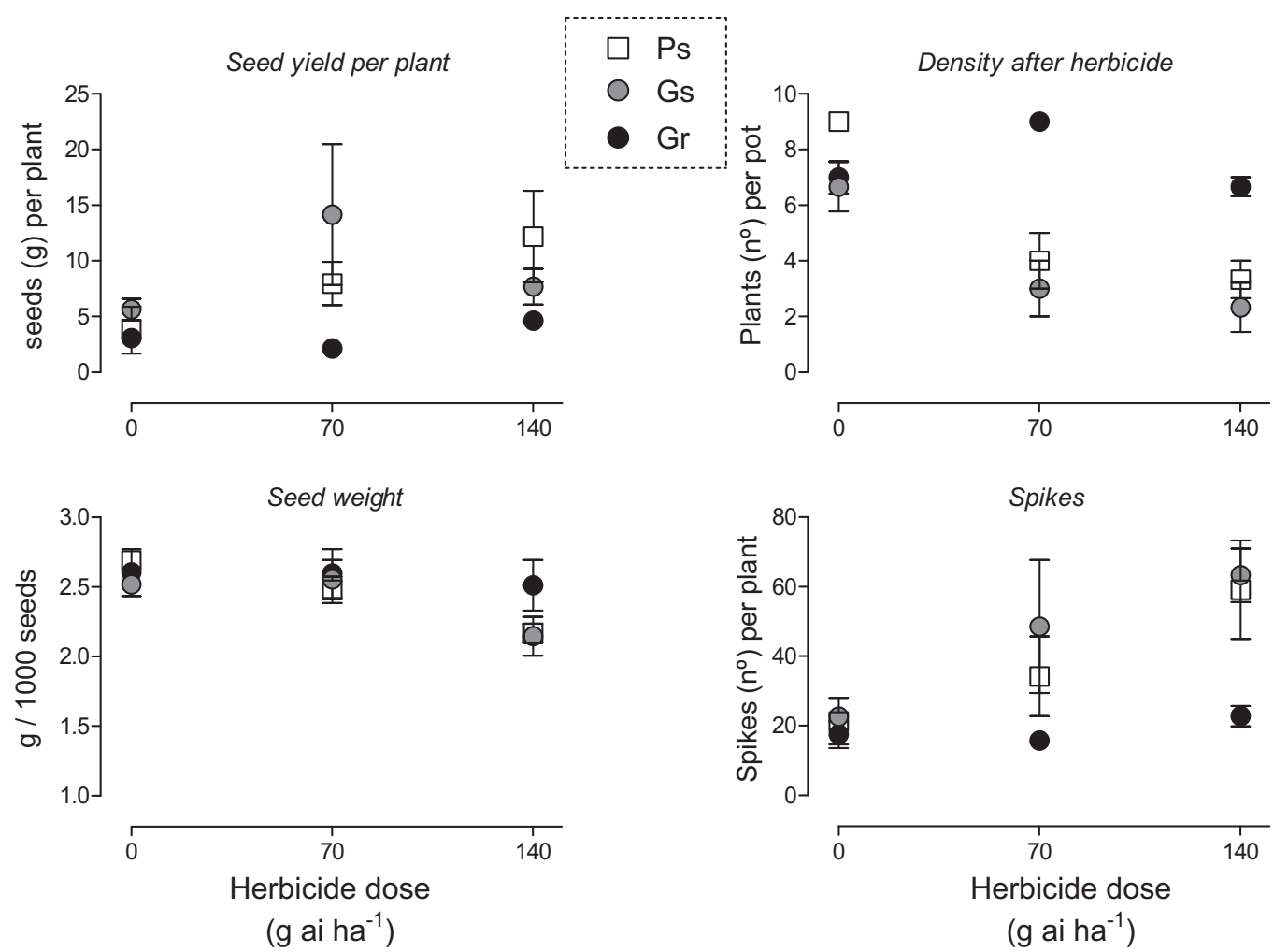

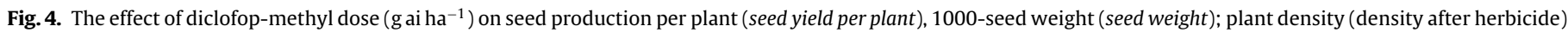
and number of spikes per plant (spikes) of Lolium multiflorum plants from Ps, Gs and Gr crosses. Values are expressed per plant, and are averages for three pots ( \pm s.e.). 

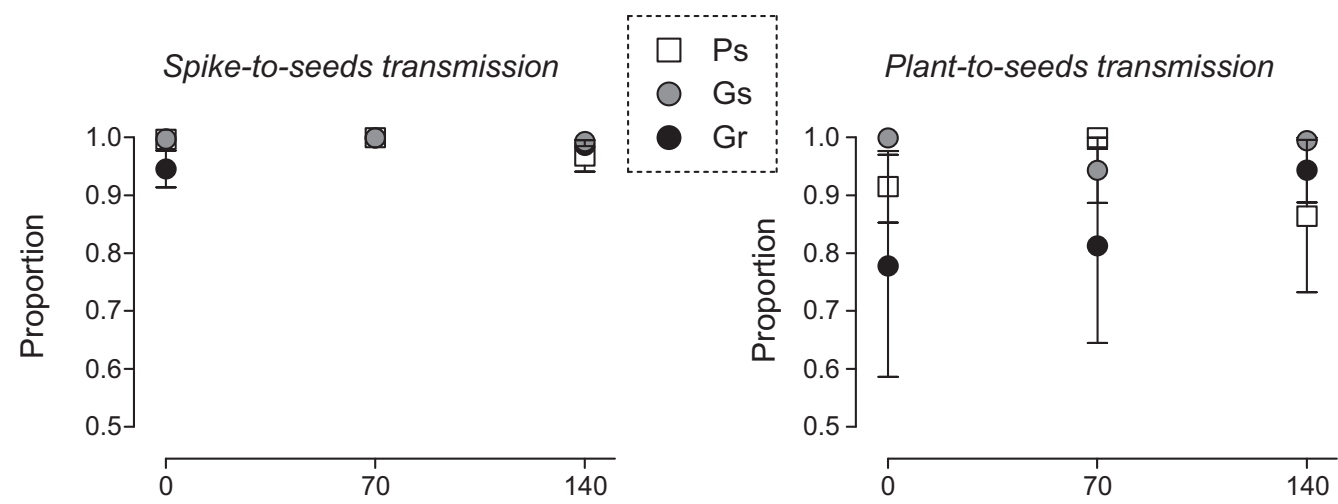

Plant-to-spikes transmission

Relative yield of E+ spikes
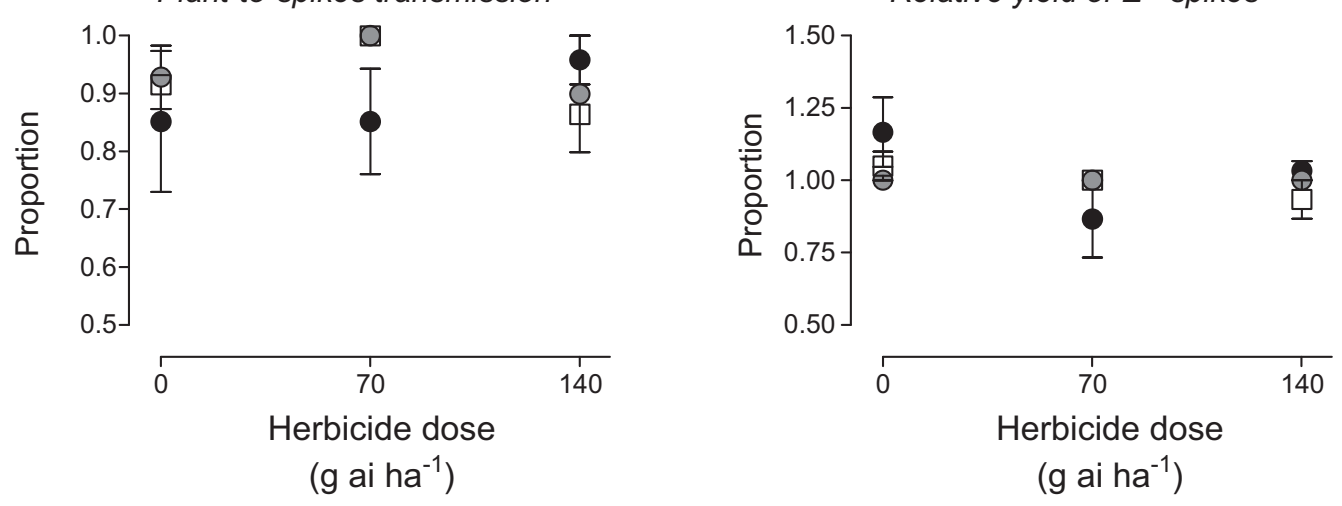

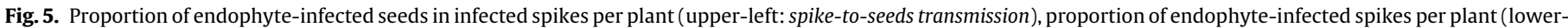

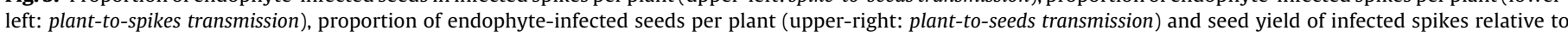

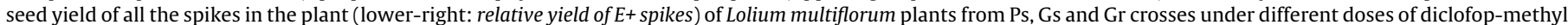
Values are expressed per plant, and are averages for three pots ( \pm s.e.).

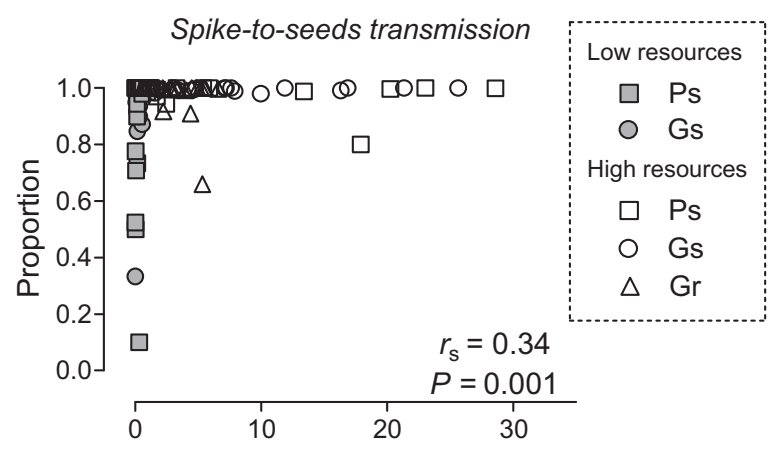

Plant-to-spikes transmission

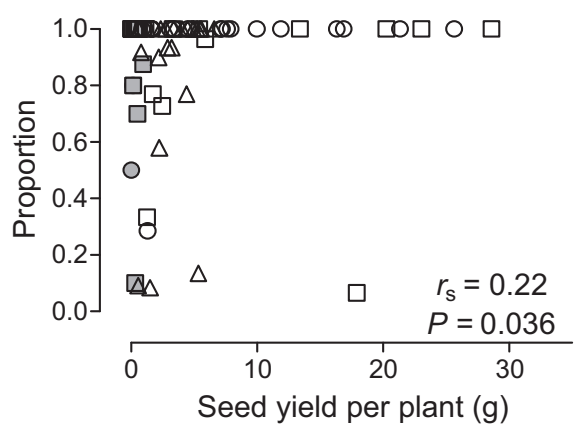

Plant-to-seeds transmission

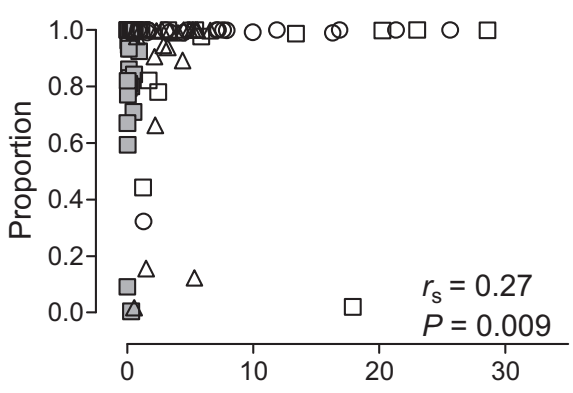

Relative yield of E+ spikes

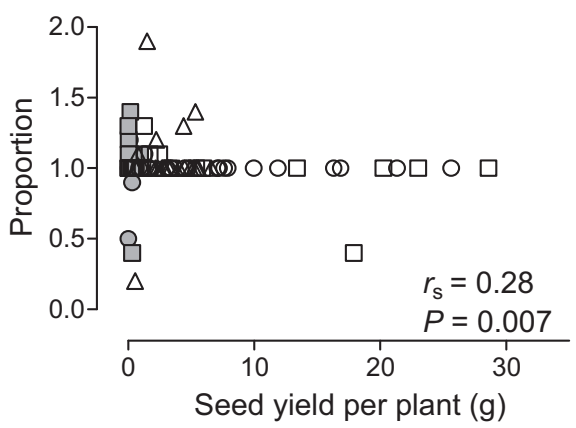

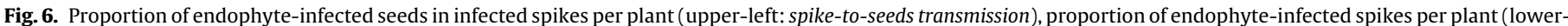

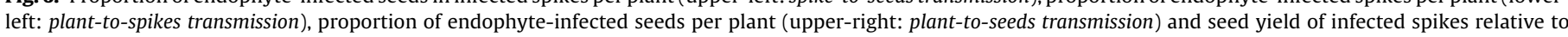

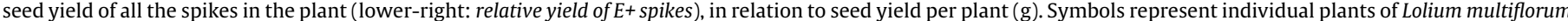

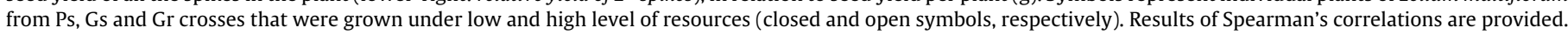


In spite of our small data set and small size effect, we clearly show that the vertical transmission of the endophyte Neotyphodium and its components decreases with plant yield under low level of resources. Moreover, we show that a herbicide causing oxidative stress did have neither a direct impact on the endophyte (a nontarget organism) nor an indirect impact on transmission efficiency through a change in plant density. Survival to herbicide application of susceptible plants resulted in high yields, whereas part of the low yielding plants corresponded to the resistant genotype. Our data suggest that herbivory, by reducing plant competition and releasing resources (soil nutrients and light), could also promote plant spike number and, in consequence, high transmission efficiency. However, L. multiflorum plants usually produce less than $3 \mathrm{~g}$ seeds (Vila-Aiub et al., 2005), which suggests that variations in the transmission rate could explain variations in the frequency of endophytes in grass populations under natural conditions.

Crossing different genotypes with a single endophyte-infected mother plant population and keeping its natural genetic diversity, allows for testing the genetic specificity and sheds light on the implications of the differential gene flow rate between partner populations. In general, genetic background had little effect on endophyte transmission. In some cases the change of genetic background resulted in indirect benefits for the endophyte by improving plant survival (in resistant populations) or increasing the host seed yield per plant (in susceptible populations under high level of resources). Crossing infected plants with genotypically distant plants had an overall multiplicative effect on the number of seeds infected with the endophyte, although no statistically significant differences were found in each component of endophyte fitness when separately analyzed. Cross-pollination among host grasses has been viewed as an opposite force to the genetic specificity between Neotyphodium endophyte and its host, directly threatening the stability of the mutualism (Faeth and Sullivan, 2003; Saikkonen et al., 2004). Despite the hybrid nature of most Neotyphodium endophytes, their chances to create genetic variability are relatively low, and probably negligible in the short term, because they reproduce clonally. However, as they are well adapted to the host apoplastic environment, they could depend on the ability of the host to evolve (Christensen et al., 2002; Clay and Schardl, 2002; Easton, 2007). Considering that hybridization between genetically distant plants is a fitness trait in self-incompatible species (Ellstrand and Schierenbeck, 2000), it should be the host population that, by means of the wind cross-pollination mechanism, are able to face the ecological heterogeneity and evolve in response to different environmental selection pressures (Gundel et al., 2010).

High infection frequency in grass populations has been associated to the positive effect of the endophyte on host plants, while low infection frequency has usually been associated with the endophyte costs when populations are growing in extremely poor or marginal environments (Bazely et al., 2007; Novas et al., 2007; Koh and Hik, 2007). However, given that it is possible to reach a high endophyte infection frequency with a tiny differential fitness between infected and non-infected plants and efficient transmission (Gundel et al., 2008), it is understandable why it has been difficult to find a good match between the level of infection frequency and the mutualistic effect (Faeth and Sullivan, 2003; Faeth and Hamilton, 2006). On the other hand, low infection frequency can be perfectly explained by failures in the transmission process (Ravel et al., 1997; Afkhami and Rudgers, 2008; Gundel et al., 2008, 2009). Despite the scarce experimental evidence supporting that transmission may be an energy-demanding process (s.l. costs; Cheplick, 2007), it is possible to expect that plants have a way to sanction the endophyte or alternatively (and not necessarily exclusive) work as a mechanism for decoupling the fitness of both partners when energy compromises arise due to extreme resource limitations. Under these extreme conditions a trait that reduces transmission efficiency would act as an extinction risk avoidance mechanism that in the long term would benefit both the host population and the mutualism.

\section{Acknowledgements}

We thank Victoria Pugliese for the grass plant drawing, and to Mariana Gundel for her assistance in the experiments. The SSR analysis was provided by R. Cuyeu, E. Pagano, and R. Ríos as a collaboration. We also thank two anonymous reviewers who greatly improved the manuscript. This study was financially supported by grants UBACyT 060 and PICT 00150 from University of Buenos Aires and FONCyT, Argentina.

\section{Appendix A.}

Forty-five micro-satellites (SSR, single sequence repeats) were used to study polymorphic variability among populations. Although not used in this work, the polymorphic study included a third Lolium multiflorum population, the commercial variety Marshall and its susceptible and resistant isolines to the diclofopmethyl herbicide (Gundel et al., unpublished data). Seventy-eight plants for the Ps population and 39 plants (treated as a bulk) for Ms, Mr, Gs and Gr populations were analyzed. The information was compared through a cluster analysis that estimates genetic distances among them. The Pampean population was genetically different from the two commercial varieties, Marshall and Gulf. The var. Gulf was the genetically most distant in relation to the Ps population and the difference between resistant and susceptible isolines was lower. Results show the genetic differences among the $L$. multiflorum populations used for plant crosses in these experiments.

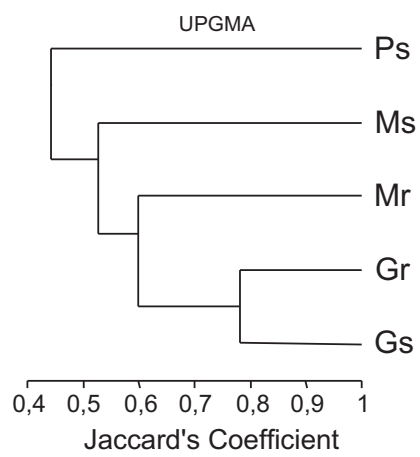

\section{References}

Adams, E., Roldán-Ruiz, I., Depicker, A., Van Bockstaele, E., De Loose, M., 2000. A maternal factor conferring resistance to crown rust in Lolium multiflorum cv. “Axis". Plant Breed. 119, 182-184.

Afkhami, M.E., Rudgers, J.A., 2008. Symbiosis lost: imperfect vertical transmission of fungal endophytes in grasses. Am. Nat. 172, 405-416.

Ball, O.J.-P., Prestidge, R.A., Sprosen, J.M., 1995. Interrelationships between Acremonium lolii, Peramine, and Lolitrem B in Perennial Ryegrass. Appl. Environ. Microb. 61 (4), 1527-1533.

Bazely, D.R., Ball, J.P., Vicari, M., Tanentzap, A.J., Bérenger, M., Rakocevic, T., Koh S., 2007. Broad-scale geographic patterns in the distribution of verticallytransmitted, asexual endophytes in four naturally-occurring grasses in Sweden. Ecography 30 (3), 367-374.

Cheplick, G.P., 2007. Costs of fungal endophyte infection in Lolium perenne genotypes from Eurasia and North Africa under extreme resource limitation. Environ. Exp. Bot. 60 (2), 202-210.

Christensen, M.J., Bennett, R.J., Schmid, J., 2002. Growth of Epichloë/Neotyphodium and p-endophytes in leaves of Lolium and Festuca grasses. Mycol. Res. 106 (1), 93-106.

Clay, K., Schardl, C., 2002. Evolutionary origin and ecological consequences of endophyte symbiosis with grasses. Am. Nat. 160, 99-127.

Crawley, M.J., 2007. The R Book. John Wiley \& Sons Ltd., UK.

di Menna, M.E., Waller, J.E., 1986. Visual assessment of seasonal changes in amount of mycelium of Acremonium loliae in leaf sheaths of perennial ryegrass. N. Z. J. Agric. Res. 29, 111-116.

do Valle Ribeiro, M.A.M., 1993. Transmission and survival of Acremonium and the implications for grass breeding. Agric. Ecosyst. Environ. 44, 195-213. 
Easton, H.S., 2007. Grasses and Neotyphodium endophytes: co-adaptation and adaptive breeding. Euphytica 154, 295-306.

Ellstrand, N.C., Schierenbeck, K.A., 2000. Hybridization as a stimulus for the evolution of invasiveness in plants? Proc. Natl. Acad. Sci. U. S. A. 97 (13), 7043-7050.

Faeth, S.H., Hamilton, C.E., 2006. Does an asexual endophyte symbiont alter life stage and long-term survival in a perennial host grass? Microb. Ecol. 52, 748-755.

Faeth, S.H., Sullivan, T.J., 2003. Mutualistic asexual endophytes in a native grass are usually parasitic. Am. Nat. 161 (2), 310-325.

Gundel, P.E., Batista, W.B., Texeira, M., Martínez-Ghersa, M.A., Omacini, M., Ghersa, C.M., 2008. Neotyphodium endophyte infection frequency in annual grass populations: relative importance of mutualism and transmission efficiency. Proc. R. Soc. Lond. B: Biol. 275, 897-905.

Gundel, P.E., Garibaldi, L.A., Tognetti, P.M., Aragón, R., Ghersa, C.M., Omacini, M., 2009. Imperfect vertical transmission of the endophyte Neotyphodium in exotic grasses in grasslands of the Flooding Pampa. Microb. Ecol. 57 (4), 740-748.

Gundel, P.E., Omacini, M., Sadras, V.O., Ghersa, C.M., 2010. The interplay between the effectiveness of the grass-endophyte mutualism and the genetic variability of the host plant in an agronomic context. Evol. Appl. 3 (5-6), 538-546.

Harper, J.L., 1977. Population Biology of Plants. Academic Press, London, UK.

Herre, E.A., Knowlton, N., Mueller, U.G., Rehner, S.A., 1999. The evolution of mutualisms: exploring the paths between conflict and cooperation. Trends Ecol. Evol. $14(2), 49-53$.

Hiatt, E.E., Hill, N.S., 1997. Neotyphodium coenophialum mycelial protein and herbage mass effects on ergot alkaloid concentration in tall fescue. J. Chem. Ecol. 23 (12), 2721-2736.

Hill, N.S., Bouton, J.H., Hiatt III, E.E., Kittle, B., 2005. Seed maturity, germination, and endophyte relationships in tall fescue. Crop Sci. 45, 859-863.

Ju, H.-J., Hill, N.S., Abbott, T., Ingram, K.T., 2006. Temperature influences on endophyte growth in tall fescue. Crop Sci. 46, 404-412.

Koh, S., Hik, D.S., 2007. Herbivory mediates grass-endophyte relationships. Ecology 88 (11), 2752-2757.

Koh, S., Vicari, M., Ball, J.P., Rakocevic, T., Zaheer, S., Hik, D.S., Bazely, D.R., 2006. Rapid detection of fungal endophytes in grasses for large-scale studies. Funct. Ecol. 20, $736-742$.
Moon, C.D., Scott, D.B., Schardl, C.L., Christensen, M.J., 2000. The evolutionary origins of Epichlöe endophytes from annual ryegrasses. Mycologia 92, 1103-1118.

Novas, M.V., Collantes, M., Cabral, D., 2007. Environmental effects on grass-endophyte associations in the harsh conditions of south Patagonia. FEMS Microbiol. Ecol. 61, 164-173.

Powles, S.B., Holtum, J.A., 1994. Herbicide Resistance in Plants; Biology and Biochemistry. Lewis Publishers, Boca Raton, USA

Puentes, A., Bazely, D.R., Huss-Danell, K., 2007. Endophytic fungi in Festuca pratensis grown in Swedish agricultural grasslands with different managements. Symbiosis $44,121-126$.

Rasmussen, S., Parsons, A.J., Bassett, S., Christensen, M.J., Hume, D.E., Johnson, L.J., Johnson, R.D., Simpson, W.R., Stacke, C., Voisey, C.R., Xue, H., Newman, J.A., 2007. High nitrogen supply and carbohydrate content reduce fungal endophyte and alkaloid concentration in Lolium perenne. New Phytol. 173, 787-797.

Ravel, C., Michalakis, Y., Charmet, G., 1997. The effect of imperfect transmission on the frequency of mutualistic seed-borne endophytes in natural populations of grasses. OIKOS $80,18-24$

Redfearn, D.D., Venuto, B.C., Pitman, W.D., Alison, M.W., Ward, J.D., 2002. Cultivar and environment effects on annual ryegrass forage yield, yield distribution, and nutritive value. Crop Sci. 42, 2049-2054.

Saikkonen, K., Wäli, P., Helander, M., Faeth, S.H., 2004. Evolution of endophyte-plant symbioses. Trends Plant Sci. 9 (6), 275-280.

Shimabukuro, R.H., Hoffer, B.L., Biewer, K.A., Davis, D.G., 1999. Physiological responses of resistant and susceptible plants to diclofop-methyl and its antagonism by 2,4-D and antioxidants. Physiol. Plantarum 107, 68-76.

Vila-Aiub, M.M., Martínez-Ghersa, M.A., Ghersa, C.M., 2003. Evolution of herbicide resistance in weeds: vertically transmitted fungal endophytes as genetic entities. Evol. Ecol. 17, 441-456.

Vila-Aiub, M.M., Gundel, P.E., Ghersa, C.M., 2005. Fungal endophyte infection changes growth attributes in Lolium multiflorum Lam. Aust. Ecol. 30, 49-57.

Welty, R.E., Craig, A.M., Azevedo, M.D., 1994. Variability of ergovaline in seeds and straw and endophyte infection in seeds among endophyte-infected genotypes of tall fescue. Plant Dis. 78 (9), 845-849. 